\title{
HPV-16 Infection Is Associated with a High Content of CD39 and CD73 Ectonucleotidases in Cervical Samples from Patients with CIN-1
}

\author{
María de Lourdes Mora-García, ${ }^{1}$ Sofía López-Cisneros, ${ }^{2}$ Vianey Gutiérrez-Serrano, ${ }^{1,2}$ \\ Rosario García-Rocha, ${ }^{1,2}$ Benny Weiss-Steider, ${ }^{1}$ Jorge Hernández-Montes ${ }^{\mathbb{D}}{ }^{1}$ \\ Héctor I. Sánchez-Peña, ${ }^{3}$ Luis Roberto Ávila-Ibarra, ${ }^{2,4}$ Christian Azucena Don-López, ${ }^{1}$ \\ Ricardo Muñóz-Godínez, ${ }^{2,4}$ Daniela Berenice Torres Pineda, ${ }^{2,4}$ \\ Rommel Chacón-Salinas $\mathbb{D}^{5},{ }^{5,6}$ Luis Vallejo-Castillo $\mathbb{D}^{\mathbb{D},}{ }^{5,7}$ Sonia Mayra Pérez-Tapia, ${ }^{5,6}$ \\ and Alberto Monroy-García $\mathbb{D}^{1,2}$ \\ ${ }^{1}$ Laboratorio de Inmunobiología, UIDCC-UMIEZ, FES-Zaragoza, UNAM, Ciudad de México, Mexico \\ ${ }^{2}$ Laboratorio de Inmunología y Cáncer, Unidad de Investigación Médica en Enfermedades Oncológicas, CMN SXXI, \\ Instituto Mexicano del Seguro Social, Ciudad de México, Mexico \\ ${ }^{3}$ Departamento de Ginecología, HGZ No. 2-A Troncoso, IMSS, Ciudad de México, Mexico \\ ${ }^{4}$ Programa de Posgrado en Ciencias Biológicas, UNAM, Ciudad de México, Mexico \\ ${ }^{5}$ Unidad de Desarrollo e Investigación en Bioprocesos (UDIBI), Instituto Politécnico Nacional, Ciudad de México, Mexico \\ ${ }^{6}$ Departamento de Inmunología, Escuela Nacional de Ciencias Biológicas-Instituto Politécnico Nacional (ENCB-IPN), \\ Ciudad de México, Mexico \\ ${ }^{7}$ Departamento de Farmacología, Centro de Investigación y de Estudios Avanzados del IPN (Cinvestav-IPN), \\ Ciudad de México, Mexico
}

Correspondence should be addressed to Alberto Monroy-García; albertomon@yahoo.com

Received 21 December 2018; Revised 14 March 2019; Accepted 9 April 2019; Published 7 May 2019

Academic Editor: Mirella Giovarelli

Copyright ( 2019 María de Lourdes Mora-García et al. This is an open access article distributed under the Creative Commons Attribution License, which permits unrestricted use, distribution, and reproduction in any medium, provided the original work is properly cited.

The development of cervical cancer (CeCa) is associated with high-risk human papilloma virus (HR-HPV) infections, mainly HPV-16, which is present in more than $50 \%$ of cases. The presence of immunosuppressive factors in the early stages of the disease is also strongly linked to CeCa progression. In this context, it is unknown whether ectonucleotidases CD39 and CD73, which are involved in the production of adenosine (Ado) that suppresses the specific antitumor immune response, are present in precursor lesions of CeCa. In this pilot study, we analyzed the presence of CD39 and CD73 and their capacity to generate Ado in 25 cervical samples from patients with grade 1 cervical intraepithelial neoplasms (CIN-1) and 25 samples from normal donors (NDs) free of HPV infection. Cells obtained from cervical samples of CIN-1 patients positive for HPV-16 showed higher CD39 and CD73 contents compared to samples obtained from CIN-1 patients negative for HPV-16 and NDs. Interestingly, solubilized cervical mucus from these patients also showed higher contents of soluble CD39 and CD73, which were associated with a greater capacity to produce Ado from the hydrolysis of adenosine triphosphate (ATP) and adenosine monophosphate (AMP). In addition, serum samples of these patients showed higher levels of TGF- $\beta$ than those of CIN-1 patients negative for HPV-16 and ND. These results suggest that persistent infection with HR-HPV, mostly HPV-16, in CIN-1 patients may promote the expression of CD39 and CD73 through the production of TGF- $\beta$ in precursor lesions to generate an immunosuppressive microenvironment and allow its progression to CeCa. 


\section{Introduction}

Cervical cancer $(\mathrm{CeCa})$ is the fourth cause of cancer death in women worldwide, accounting for more than 300,000 deaths per year, of which more than $80 \%$ occur in developing countries $[1,2]$. Persistent infection due to human papilloma virus (HPV) is the main factor for developing CeCa. To date, more than $200 \mathrm{HPV}$ genotypes have been identified, of which HPV-16, HPV-18, HPV-31, HPV-33, HPV-35, HPV-39, HPV-45, HPV-51, HPV-52, HPV-56, and HPV-58, which are considered high-risk HPV (HR-HPV), are associated with anogenital cancer [3-5].

Most HPV infections are eliminated by the immune system in approximately 1 or 2 years after exposure [6]. However, in rare cases, HPV can generate dysplastic changes in the cervix, known as cervical intraepithelial neoplasia (CIN), classified as CIN-1, CIN-2, or CIN-3 [7]. CIN lesions are clinically heterogeneous and may regress spontaneously or persist and progress to invasive cancer. The regression rates vary according to the degree, occurring in approximately $50-90 \%$ of women with CIN-1, 40\% with CIN-2, and 30\% with CIN-3 [8]. In this context, the immune system plays a significant role by eradicating HPV infection, even with established CIN; however, it has been proposed that the progression to $\mathrm{CeCa}$ is inevitably linked to an immunosuppressive microenvironment during carcinogenesis in the cervix [9]. Therefore, it is important to determine the molecular mechanisms involved in immunosuppression in the initial stages of $\mathrm{CeCa}$.

Recent reports have shown that the adenosinergic pathway plays an important role in the pathogenesis of gynecological cancer [10]. In this pathway, Ado generated through the phosphohydrolysis of adenine nucleotides by the activity of CD39 ectoenzymes (ENTPD1, ectonucleoside triphosphate diphosphohydrolase-1, EC 3.6.1.5) and CD73 (5'-ectonucleotidase, EC 3.1.3.5) induces extracellular signaling through four Ado receptors (ARs: A1R, A2AR, A2BR, and $A 3 R$ ) coupled to $G$ proteins and arranged in the membranes of target cells [11]. In the hypoxic tumor microenvironment, Ado exerts an immunosuppressive effect on the effector cells of the immune system by interacting with A2AR [12] in addition to participating in the promotion of tumor growth inducing proliferation, invasion, and metastasis of tumor cells $[13,14]$. Our working group was the first to report that $\mathrm{CeCa}$ tumor cells positive for HPV-16 and HPV-18 produce higher levels of CD73 than those negative for HPV and strongly suppress the effector functions of cytotoxic T lymphocytes through the production of Ado. Furthermore, by silencing the E6 and E7 oncogenes in these tumor cells, the expression level of CD73 and its ability to produce Ado were strongly reduced, suggesting that HPV infection may favor the constitutive expression of CD73 in cervical neoplasms to contribute to the suppression of the immune response through the production of Ado [15]. To determine whether the presence of CD39 and CD73 is related to HPV infection in the early stages of $\mathrm{CeCa}$, we analyzed the contents and hydrolytic activity of these ectonucleotidases in cervical samples from patients with CIN-1. For comparison purposes, cervical samples from NDs negative for HPV were also analyzed.

\section{Methods}

This was a cross-sectional, descriptive, and observational pilot study.

2.1. Biological Material. The study population was selected among patients who visited the Department of Gynecology of HGZ No. 2-A Troncoso, Mexican Social Security Institute (IMSS), Mexico City, Mexico. Cervical cytology samples were obtained between February 2016 and February 2018 after obtaining informed consent endorsed by the local bioethics committee. All women underwent cytological and histopathological analyses by means of a directed colposcopy. Two experienced cytotechnologists independently examined all Papanicolaou tests. Samples with an inconsistent diagnosis were excluded from the study. The cytology diagnoses were classified according to the Bethesda system, while a CIN-1 histopathological diagnosis was classified according to Richardt [16]. Women who were consistently negative to clinical and molecular tests were considered ND. Only CIN-1 patients who tested positive for HPV through polymerase chain reaction (PCR) were included in the study. Samples from patients with CIN-2 or CIN-3 were excluded from the study. Cervical cells were carefully collected by cleaning the ectocervix with a cytobrush (Cytobrush ${ }^{\circledR}$, STERYLMEDICAL Co., Yangon, Myanmar). Samples were placed in a tube containing $2 \mathrm{~mL}$ of sterile phosphatebuffered saline (PBS) (Sigma-Aldrich, St. Louis, MO, USA) free of contamination to solubilize the mucus. Once the samples were centrifuged at $2000 \mathrm{rpm}$, the cell pellet was placed in a tube containing ThinPrep ${ }^{\circledR}$ PreservCyt ${ }^{\circledR}$ (Hologic Inc., Marlborough, MA, USA), while the supernatants were fractionated into tubes and stored at $-20^{\circ} \mathrm{C}$ for the detection and determination of the hydrolytic activity of soluble CD39 and CD73. A portion of cells was used for immunocytochemical staining and another for further processing in TRIzol $^{\circledR}$ (Thermo Fisher Scientific, Waltham, MA, USA). DNA was extracted from TRIzol $^{\circledR}$ by the traditional phenol-chloroform technique. All samples were subjected to PCR molecular analysis, using the LINEAR ARRAY ${ }^{\circledR}$ HPV kit (Roche Diagnostics, CA, USA), for genotyping between 37 main types of HPV that infect the anogenital region (HPV-6, HPV-11, HPV-16, HPV-18, HPV-26, HPV-31, HPV-33, HPV-35, HPV-39, HPV-40, HPV-42, HPV-45, HPV-51, HPV-52, HPV-53, HPV-54, HPV-55, HPV-56, HPV-58, HPV-59, HPV-61, HPV-62, HPV-64, HPV-66, HPV-67, HPV-68, HPV-69, HPV-70, HPV-71, HPV-72, HPV-73, HPV-81, HPV-82, HPV-83, and HPV-84), following the supplier's instructions.

2.2. Detection of CD39 and CD73 in Cervical Cytologies. The expression of ectonucleotidases CD39 and CD73 in cervical cells was determined by immunocytochemical staining with a mouse anti-CD39 monoclonal antibody (clone eBioA1 (A1), 14-0399-82, eBioscience) (Thermo Fisher Scientific, Waltham, MA USA) and an anti-CD73 rabbit-derived polyclonal antibody (Cat. NBP1-85740) (Novus Biologicals, Cambridge, UK) according to protocols previously described $[17,18]$. Briefly, $5 \times 10^{3}$ cervical cells fixed in ThinPrep 
TABLE 1: Clinical data of patients with CIN-1 and the HPV genotyping of their cervical samples.

\begin{tabular}{|c|c|c|c|c|}
\hline Cervical sample number & HPV genotypes & Age (years) & Number of sexual partners & Number of pregnancies \\
\hline 1 & 16 & 36 & 4 & 3 \\
\hline 2 & 16 & 29 & 2 & 2 \\
\hline 3 & 16 & 43 & 3 & 2 \\
\hline 4 & 16 & 32 & 3 & 2 \\
\hline 5 & $16,54,56,83$ & 19 & 2 & 4 \\
\hline 6 & 16 & 25 & 3 & 3 \\
\hline 7 & 16 & 39 & 3 & 3 \\
\hline 8 & 16 & 28 & 4 & 2 \\
\hline 9 & $16,33,35,52,58,61$ & 27 & 3 & 2 \\
\hline 10 & $16,33,35,52,58,61$ & 19 & 2 & 2 \\
\hline 11 & $16,33,35,52,58,61$ & 29 & 3 & 2 \\
\hline 12 & $33,35,52,54,58,62$ & 31 & 1 & 2 \\
\hline 13 & 2,61 & 21 & 2 & 1 \\
\hline 14 & 58 & 20 & 2 & 1 \\
\hline 15 & 52 & 24 & 2 & 1 \\
\hline 16 & 18 & 40 & 3 & 2 \\
\hline 17 & 52 & 41 & 2 & 1 \\
\hline 18 & 58 & 20 & 2 & 1 \\
\hline 19 & 18,54 & 37 & 2 & 0 \\
\hline 20 & 39 & 42 & 2 & 1 \\
\hline 21 & 53 & 33 & 2 & 1 \\
\hline 22 & $39,53,70$ & 26 & 1 & 1 \\
\hline 23 & $33,35,52,58,59$ & 34 & 3 & 1 \\
\hline 24 & 53 & 27 & 2 & 1 \\
\hline 25 & $39,53,70$ & 39 & 2 & 2 \\
\hline Averages & & 30.4 & 2.4 & 1.72 \\
\hline
\end{tabular}

PreservCyt ${ }^{\circledR}$ solution were deposited onto positively charged glass slides (Kling-On HIER Slides, Biocare Medical). Subsequently, the cells were permeated with $0.01 \%$ Triton X-100 in PBS and incubated for $2 \mathrm{~h}$ with $2 \%(w / v)$ bovine serum albumin (BSA) in PBS (Sigma-Aldrich, St. Louis, MO, USA). Next, the cells were incubated for $1 \mathrm{~h}$ with the antibodies. After two washes with PBS, the slides were incubated for 1 $h$ using goat anti-mouse or anti-rabbit secondary antibodies conjugated to horseradish peroxidase (Dako, Carpinteria, CA, USA). The development was carried out with a substrate-chromogen solution, 3,3'-diaminobenzidine dihydrochloride (DAB) (Sigma-Aldrich, St. Louis, MO, USA), for 3-5 min. Cells incubated with the correspondent secondary antibody were included as a control. Nuclei were stained with Mayer's hematoxylin (Sigma-Aldrich, St. Louis, MO, USA). The slides were scanned through an Aperio CS digital pathology device (San Diego, CA, USA) to obtain electronic files. The presence of proteins CD73 and CD39 in the cervical cells was determined by densitometric analysis considering the total expression density (TED) from 100 cells per sample using Image-Pro Plus version 6.0.

2.3. Detection of Soluble CD39 and CD73. The content of ectonucleotidases CD39 and CD73 solubilized in supernatants of cervical samples was determined by an enzyme-linked immunosorbent assay (ELISA). Data were interpolated in type curves of recombinant enzymes CD39 and CD73 (R\&D Systems, Minneapolis, MN, USA) using different concentrations (1-100 ng/mL) diluted in PBS. To detect the content of soluble CD39 and CD73 in cervical samples, we previously determined the total protein concentration in each supernatant by using the Bradford reagent (Sigma-Aldrich, St. Louis, MO, USA). Afterwards, $2 \mu \mathrm{g}$ of total protein (in a final volume of $100 \mu \mathrm{L}$ ) placed in triplicate in 96-well flat-bottomed plates for the ELISA/RIA (Corning Inc., USA) was incubated for $1 \mathrm{~h}$ at $37^{\circ} \mathrm{C}$ and then overnight at $4^{\circ} \mathrm{C}$. Next, the plates were washed with wash solution (PBS-0.1\% Tween-20) and then incubated with blocking solution (2\% BSA $w / v$ in PBS-0.1\% Tween-20) for $2 \mathrm{~h}$ at $37^{\circ} \mathrm{C}$. Once the plates were washed, anti-CD39 and antiCD73 antibodies were added at a dilution of $1: 500$ in blocking solution and incubated for $2 \mathrm{~h}$. The plates were washed six times and incubated with goat anti-mouse or anti-rabbit IgG antibodies bound to alkaline phosphatase (Thermo Fisher Scientific, Waltham, MA, USA) at a dilution of $1: 5000$. The plates were incubated at $37^{\circ} \mathrm{C}$ for an additional $2 \mathrm{~h}$, and after eight washes, the alkaline phosphatase substrate (Sigma-Aldrich, St. Louis, MO, USA) was added 
to diethanolamine solution (Sigma-Aldrich, St. Louis, MO, USA) at $10 \%$ ( $\mathrm{pH} 9.8)$. The reading was performed at a wavelength of $405 \mathrm{~nm}$ using an ELISA plate reader.

2.4. Hydrolytic Activity of Soluble CD39 and CD73. To determine the hydrolytic activity of ectonucleotidases CD39 and CD73 solubilized in cervical samples, $2 \mu \mathrm{g}$ of total protein from the supernatants of the samples collected was incubated with adenosine triphosphate (ATP) or adenosine monophosphate (AMP) at a final concentration of $5 \mathrm{mM}$. After incubation for $72 \mathrm{~h}$, Ado production was evaluated. To inhibit the enzymatic activity of CD39 and CD73, the specific inhibitors sodium polyoxotungstate (POM-1) (Sigma-Aldrich, St. Louis, MO, USA) and adenosine $5^{\prime}-(\alpha, \beta$-methylene $)$ diphosphate (APCP) (Sigma-Aldrich, St. Louis, MO, USA), respectively, were added at a final concentration of $5 \mathrm{mM}$ as previously described [19]. The total volume of each reaction was $50 \mu \mathrm{L}$. The amount of Ado produced by each sample incubated with ATP or AMP was evaluated through highperformance liquid chromatography, applying $25 \mu \mathrm{L}$ of each reaction to a chromatograph (UPLC Acquity, Waters Corporation, Milford, MA, USA) using a mobile phase composed of $0.5 \%$ acetonitrile, $5 \%$ methanol, and $94.5 \%$ sodium acetate (0.25 $\mathrm{M}$ and $\mathrm{pH}$ 6.3). Prior to the reading, the samples were filtered in Amicon filters of 3000 Daltons (Millipore Corporation, USA). An Ado standard curve was prepared to evaluate the Ado content in the different samples using Empower 3 (Waters Corporation, Milford, MA, USA).

In some assays, different concentrations ( $5 \mathrm{mM}, 0.5 \mathrm{mM}$, $0.05 \mathrm{mM}$, and $0.005 \mathrm{mM}$ ) of POM-I or APCP were used to inhibit the capacity of supernatants of cervical samples to hydrolyze ATP or AMP. The presence of the products (AMP and Ado) was detected by thin-layer chromatography (TLC) by placing $1 \mu \mathrm{L}$ of each supernatant on fluorescent gel-coated plates (Whatman, GE Healthcare, Freiburg, Germany). Samples were eluted for $1 \mathrm{~h}$ using a mobile phase composed of isobutanol:isoamyl alcohol:ethoxyethano1:ammonia: water $(9: 6: 18: 9: 15)$ [20], and $5 \mathrm{mM}$ AMP, Ado, and inosine (Ino) (Sigma-Aldrich) were used as standard controls. Compounds were visualized using an UV transilluminator.

2.5. Quantification of TGF- $\beta 1$. To quantify TGF- $\beta 1$ content in serum samples, the human TGF- $\beta 1$ Quantikine ELISA Kit (R\&D Systems) was used according to the manufacturer's protocol.

2.6. Statistical Analysis. All numerical data are presented as the mean value \pm standard error of the mean (SEM) of three independent experiments. Comparisons and correlations were evaluated by multivariate statistical analysis using GraphPad Prism version 7 (La Jolla, CA, USA). Values $<0.05$ were considered statistically significant.

\section{Results}

3.1. Participant Characteristics. The present study was performed using 50 cervical samples from women who visited the Department of Gynecology of HGZ Troncoso, IMSS, and according to the clinical assessment and
TABLE 2: Clinical data of normal donors.

\begin{tabular}{|c|c|c|c|}
\hline $\begin{array}{l}\text { Cervical sample } \\
\text { number }\end{array}$ & $\begin{array}{c}\text { Age } \\
\text { (years) }\end{array}$ & $\begin{array}{c}\text { Number of sexual } \\
\text { partners }\end{array}$ & $\begin{array}{l}\text { Number of } \\
\text { pregnancies }\end{array}$ \\
\hline 1 & 32 & 1 & 1 \\
\hline 2 & 19 & 0 & 0 \\
\hline 3 & 23 & 1 & 2 \\
\hline 4 & 24 & 0 & 0 \\
\hline 5 & 18 & 0 & 0 \\
\hline 6 & 23 & 1 & 1 \\
\hline 7 & 33 & 1 & 2 \\
\hline 8 & 28 & 1 & 2 \\
\hline 9 & 29 & 1 & 1 \\
\hline 10 & 31 & 1 & 2 \\
\hline 11 & 26 & 2 & 1 \\
\hline 12 & 30 & 1 & 1 \\
\hline 13 & 42 & 1 & 2 \\
\hline 14 & 22 & 0 & 0 \\
\hline 15 & 28 & 1 & 1 \\
\hline 16 & 41 & 1 & 3 \\
\hline 17 & 40 & 2 & 2 \\
\hline 18 & 31 & 1 & 1 \\
\hline 19 & 34 & 1 & 2 \\
\hline 20 & 44 & 2 & 2 \\
\hline 21 & 37 & 3 & 1 \\
\hline 22 & 21 & 1 & 0 \\
\hline 23 & 28 & 1 & 1 \\
\hline 24 & 28 & 1 & 1 \\
\hline 25 & 37 & 2 & 1 \\
\hline Averages & 29.9 & 1.08 & 1.2 \\
\hline
\end{tabular}

histopathological study. Twenty-five samples corresponded to women whose colposcopy was positive for CIN-1 and 25 ND samples that were negative for HPV infection and whose colposcopy was negative for CIN-1. All samples and clinical data from the participants were taken after obtaining informed consent, in accordance with the ethics and confidentiality requirements related to working with human samples from the institutions involved. The mean age of the CIN-1 patients was 30.4 (range 19-43) years (Table 1), and that of the ND group was 29.9 (range 18-44) years (Table 2). The average number of sexual partners and pregnancies reported by CIN-1 patients was 2.4 (range 1-4) and 1.72 (range 1-4), respectively (Table 1 ), while that of the ND group was 1.08 (range 1-3) and 1.2 (range 1-3) (Table 2), respectively. All cervical samples from CIN-1 patients were positive for HPV infection. The most frequent genotypes were HPV-16 (11/25, 44\%), HPV-58 and HPV-52 (7/25, 28\%), HPV-53 and HPV-61 (4/25, 16\%), and HPV-39 and HPV-54 (3/25, 12\%) (Table 1). Fifteen samples presented infection with a single HPV genotype, of which 7 presented mono-HPV-16 infection (HPV-16), and 10 samples had coinfections (CI) by two or more different HPV genotypes, of which only 4 were coinfected with HPV-16 (HPV-16+CI). On the other hand, 14 of the 25 
TABLE 3: Relation among clinical data of NDs and patients with CIN-1 with different HPV genotypes.

\begin{tabular}{|c|c|c|c|c|c|}
\hline Clinical data & NDs & HPV-16 & $\begin{array}{l}\text { CIN-1 patient } \\
\text { HPV-16+CI }\end{array}$ & HPV-16neg & $P$ values \\
\hline Age (years) & $29.96 \pm 7.26$ & $33.14 \pm 6.46$ & $23.5 \pm 5.26$ & $31.07 \pm 8.07$ & - \\
\hline Number of sexual partners & $1.08 \pm 0.7$ & $3.4 \pm 0.69^{\mathrm{a}}$ & $2.5 \pm 0.57^{b}$ & $2 \pm 0.55^{\mathrm{c}}$ & $\begin{array}{l}<0.0001 \text { vs. } \mathrm{ND}^{\mathrm{a}} \\
<0.0077 \text { vs. } \mathrm{ND}^{\mathrm{b}} \\
<0.0002 \text { vs. } \mathrm{ND}^{\mathrm{c}}\end{array}$ \\
\hline Number of pregnancies & $1.2 \pm 0.8$ & $2.4 \pm 0.53^{\mathrm{d}}$ & $2.5 \pm 1^{\mathrm{e}}$ & $1.14 \pm 0.53^{\mathrm{f}, \mathrm{g}}$ & $\begin{array}{c}<0.0008 \text { vs. } \mathrm{ND}^{\mathrm{d}} \\
<0.0077 \text { vs. } \mathrm{ND}^{\mathrm{e}} \\
<0.0001 \text { vs. } \mathrm{HPV}-16^{\mathrm{f}} \\
<0.002 \text { vs. } \mathrm{HPV}-16+\mathrm{CI}^{\mathrm{g}}\end{array}$ \\
\hline
\end{tabular}

ND: normal donors; HPV-16: CIN-1 patients positive for HPV-16; HPV-16+CI: CIN-1 patients with coinfection with HPV-16 and other HPV types; HPV-16neg: CIN-1 patients negative for HPV-16. $P$ values were calculated using the Wilcoxon signed-rank test and Student's $t$-test.

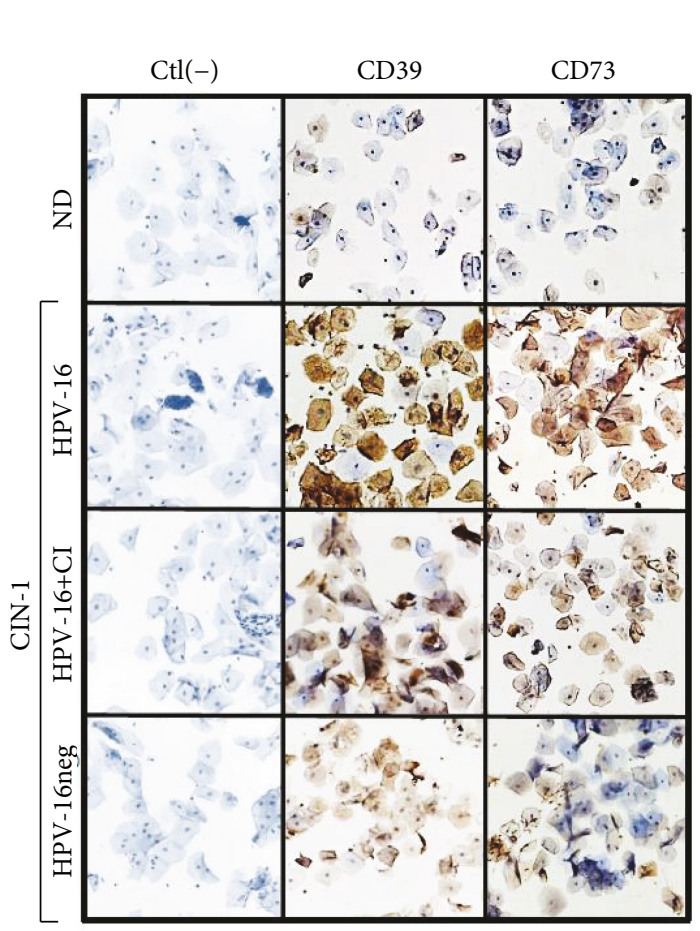

(a)

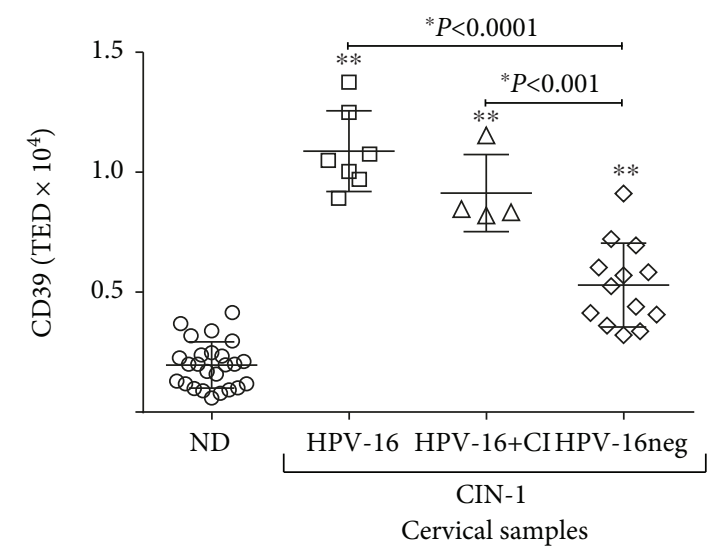

(b)

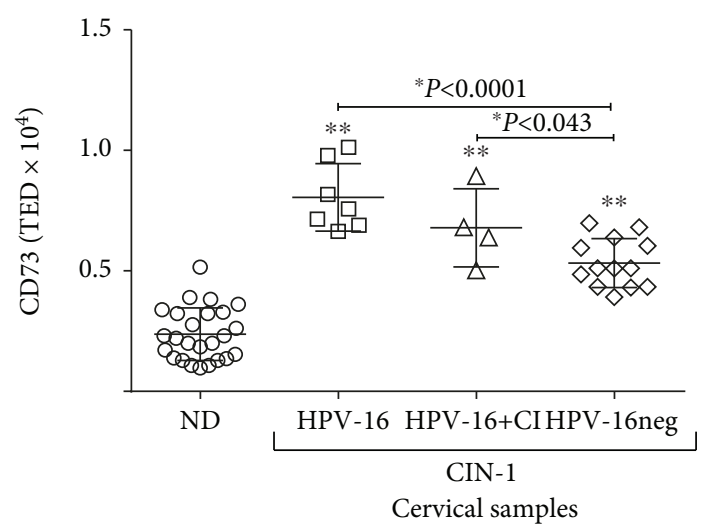

(c)

Figure 1: Expression of CD39 and CD73 in cervical cytologies of CIN-1 patients and normal donors (NDs). (a) Representative immunocytochemistry staining associated with the presence of ectonucleotidases CD39 and CD73 in cervical cytologies from NDs free of HPV infection and CIN-1 patients, positive either for HPV-16 (HPV-16) or for coinfection with HPV-16 and other HPV types (HPV-16+CI), or from HPV patients negative for HPV-16 (HPV-16neg) is shown in brown (10x magnification). Cells incubated only with the secondary antibody were included as a negative control (Ctl(-)). The presence of CD39 (b) and CD73 (c) proteins in cervical cytologies was analyzed through an Aperio AS device. The total expression density (TED) values are shown for each ND sample (circles), CIN-1 patients positive for HPV-16 (squares), patients with HPV-16+CI (triangles), and HPV-16neg patients (diamonds). * indicates a statistically significant difference between groups. $P$ values were calculated using the Wilcoxon signed-rank test and Student's $t$-test. 


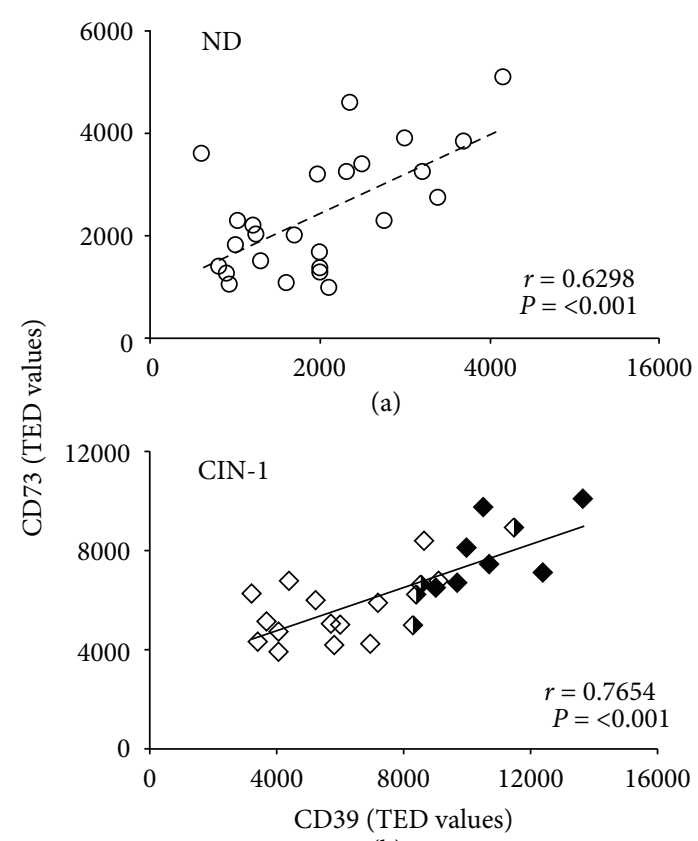

(b)

Figure 2: Correlation between the contents of CD39 and CD73 in the cytologies of CIN-1 patients and NDs. A positive $(r)$ correlation between the TED values of CD39 and CD73 is shown for (a) NDs free of HPV infection (open circles) $(r=0.6298, P<0.001)$ and (b) CIN-1 patients $(r=0.7654, P<0.001)$. The contents of CD39 and CD73 are indicated in samples from CIN-1 patients positive for HPV-16 (HPV-16, black diamonds), patients with coinfection with HPV-16 and other HPV types (HPV-16+CI, black and white diamonds), and CIN-1 patients negative for HPV-16 (HPV-16neg, white diamonds). TED: total expression density.

CIN-1 samples were negative for HPV-16 infection (HPV-16neg). It is important to mention that CIN-1 patients, positive for HPV-16, either by mono-HPV-16 or by coinfection with other HPV genotypes (HPV-16+CI), exhibited significantly a greater number of sexual partners (averages 3.4 and 2.5) and pregnancies (averages 2.4 and $2.5)$, respectively, than those of NDs, whose averages were 1 and 1.2 , respectively (Table 3 ).

3.2. Cervical Cytologies of Patients with CIN-1 and HPV-16 Infection Showed High CD39 and CD73 Contents. The presence of CD39 and CD73 was visible mainly at the membrane and in the cytoplasm (Figure 1(a)). The TED for both ectonucleotidases was significantly higher in CIN-1 patients compared to NDs. The TED averages for CD39 and CD73 in CIN-1 patients were $7606 \pm 597$ and $6379 \pm 343$ pixels, respectively, while those in NDs were $1989 \pm 194$ and $2451 \pm 234$ pixels, respectively (Figures $1(\mathrm{~b})$ and $1(\mathrm{c})$ ). In fact, in the CIN-1 patients, those with HPV-16 and HPV-16+CI showed TED values of CD39 and CD73 that were higher than the values in HPV-16neg one. However, no differences of TED values of CD39 and CD73 were observed between HPV-16 and HPV-16+CI groups (Figure 1(b) and (c)). On the other hand, we observed a positive correlation between CD39 and CD73 contents in

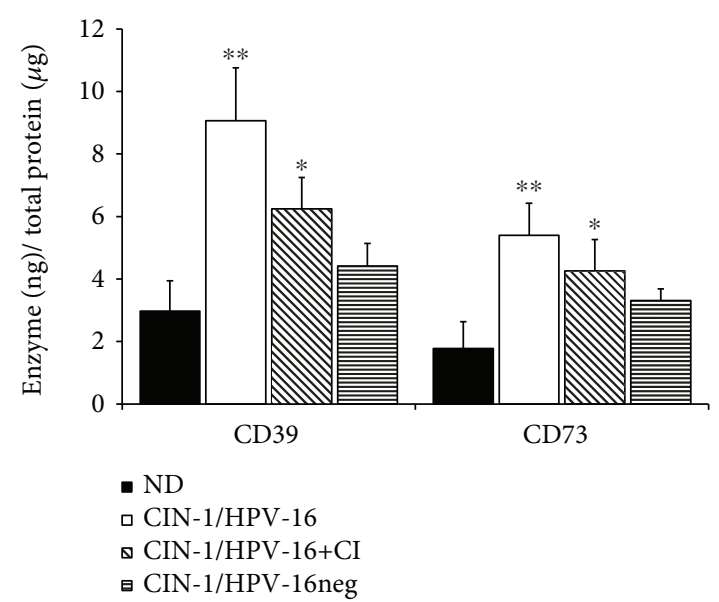

Figure 3: Contents of CD39 and CD73 in cervical samples from CIN-1 patients and NDs. The presence of CD39 and CD73 solubilized in cervical samples was determined by ELISA as described in Methods. The contents of CD39 and CD73 in cervical samples from NDs free of HPV infection (black bars) and from CIN-1 patients, positive either for HPV-16 (HPV-16, white bars) or for coinfection with HPV-16 and other HPV genotypes (HPV-16+CI, diagonal lines), or from HPV patients negative for HPV-16 (HPV-16neg, horizontal lines) are shown. Data represent three independent experiments, and the means \pm SEM are shown. $*$ indicates a significant difference $(P<0.05)$ relative to the ND group. $P$ values were calculated using the Wilcoxon signed-rank test and Student's $t$-test.

both the ND $(0.6298, P<0.001)$ (Figure $2(\mathrm{a})$ ) and CIN-1 (0.7654, $P<0.001)$ groups (Figure $2(\mathrm{~b})$ ).

3.3. Presence of Soluble CD39 and CD73 in Cervical Samples from CIN-1 Patients and NDs. The expression of oncogenes E6 and E7 in cells positive for HR-HPV significantly increases protein secretion and extracellular microvesicles that may suppress the immune response [21-23]. Considering that cytological samples from CIN-1 patients had higher levels of CD39 and CD73 than ND samples, we detected the presence of these ectonucleotidases in the supernatants of the cervical samples using ELISA and type curves of recombinant CD39 and CD73. The supernatants of cervical samples from patients with CIN-1 positive for HPV-16, either by monoHPV-16 or by coinfection with other HPV genotypes (HPV-16+CI), presented significantly higher contents $(P<0.05)$ of soluble CD39 and CD73 than those of ND samples. The contents of CD39 and CD73 in the supernatants of ND samples were $2.87 \pm 0.98$ and $1.71 \pm 0.86 \mathrm{ng} / \mu \mathrm{g}$ of total protein, respectively. Cervical samples from patients with CIN-1 positive for $\mathrm{HPV}-16, \mathrm{HPV}-16+\mathrm{CI}$, and $\mathrm{HPV}-16$ neg had $8.84 \pm 1.65$ and $5.32 \pm 0.99,6.14 \pm 0.92$ and $4.2 \pm 0.41$, and $4.3 \pm 0.76$ and $3.24 \pm 0.39 \mathrm{ng} / \mu \mathrm{g}$ of total protein, respectively (Figure 3).

3.4. Cervical Samples from Patients with CIN-1 HPV-16+ Showed a High Capacity to Generate Adenosine by the Hydrolysis of ATP and AMP. To analyze the hydrolytic activity of ectonucleotidases CD39 and CD73 solubilized in the supernatants of cervical samples from patients with CIN-1 


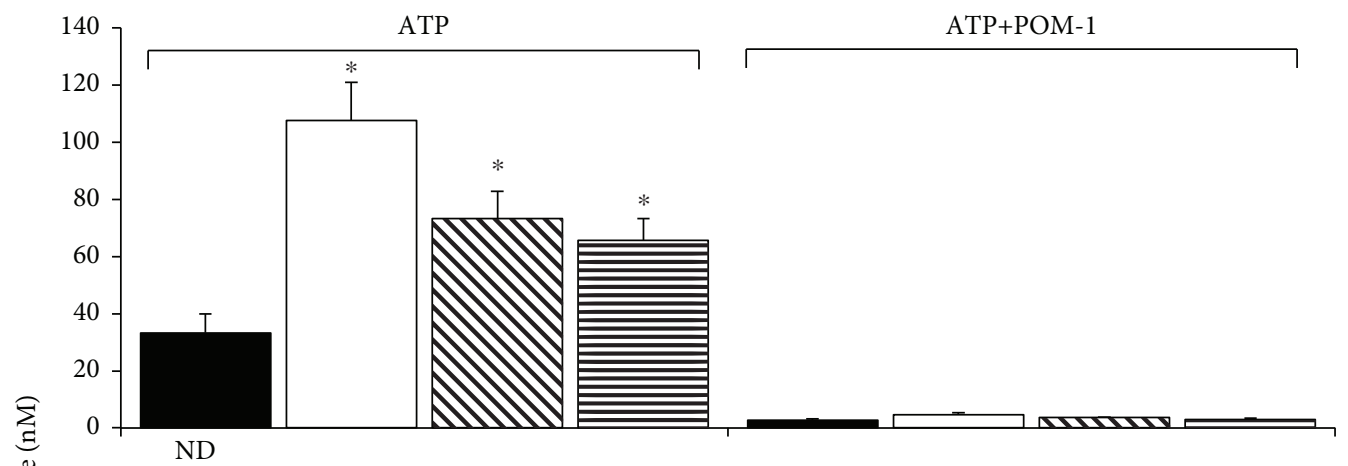

(a)

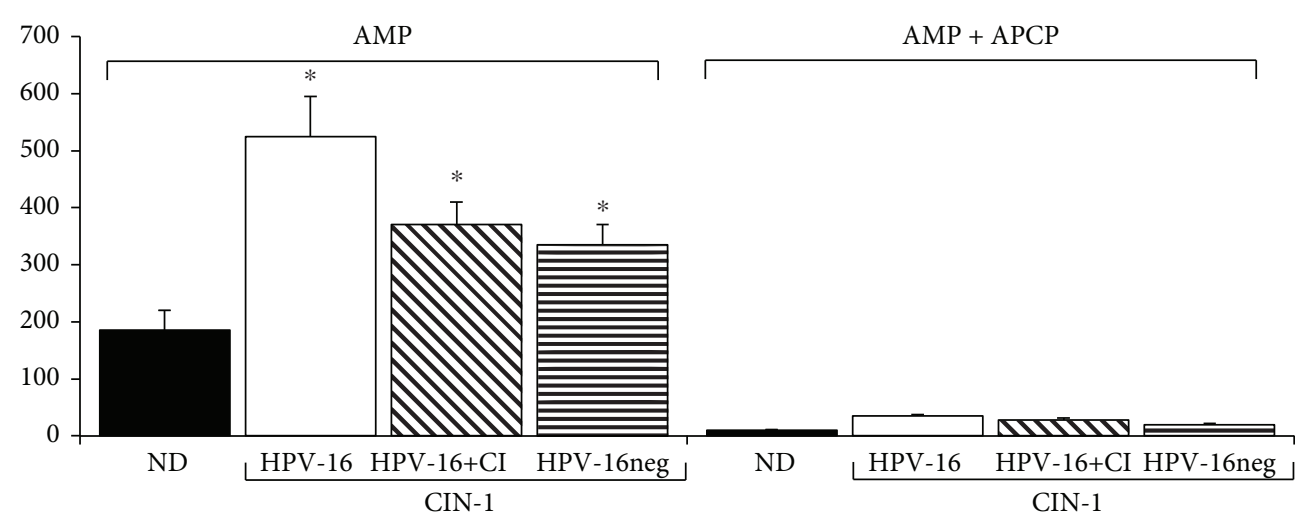

(b)

FIGURE 4: Hydrolytic activity of CD39 and CD73 solubilized in cervical samples from CIN-1 patients and NDs. Aliquots of $2 \mu \mathrm{g}$ of total protein obtained from the supernatants of cervical samples from NDs negative for HPV (ND, black bars) and CIN-1 patients, positive either for HPV-16 (HPV-16, white bars) or for coinfection with HPV-16 and other HPV types (HPV-16+CI, diagonal lines), or HPV patients negative for HPV-16 (HPV-16neg, horizontal lines) were incubated in the presence of $5 \mathrm{mM}$ of ATP or AMP and in the presence or absence of POM-I or APCP, specific inhibitors of CD39 and CD73, respectively. After $72 \mathrm{~h}$ of incubation, the Ado product of ATP (a) or AMP (b) hydrolysis was evaluated by UPLC. * indicates a significant difference $(P<0.01)$ of the Ado product of CIN-1 samples compared to NDs. Data represent three independent experiments.

and NDs, we incubated $2 \mu \mathrm{g}$ of total protein of each supernatant in the presence of $5 \mathrm{mM}$ ATP or AMP and in the presence or absence of POM-I or APCP, specific inhibitors of CD39 and CD73, respectively. Aliquots of the supernatants were taken at the beginning and after $72 \mathrm{~h}$ of incubation to evaluate Ado production by means of UPLC. Samples from CIN-1 patients exhibited a greater capacity to produce Ado than ND samples. Notably, samples from CIN-1 patients positive for HPV-16 had the highest capacity to hydrolyze ATP and AMP. The average Ado concentration produced by incubation of the supernatants from ND samples in the presence of ATP and AMP was $31.72 \pm 7.8$ and $181.16 \pm$ $56.97 \mathrm{nM}$, respectively (Figures 4(a) and 4(b)). In samples from CIN-1 patients positive for HPV-16, HPV-16+CI, and HPV-16neg, the average Ado concentration was 106.14 \pm $23.96,71.5 \pm 7.23$, and $64.21 \pm 13.41$ and $515 \pm 51.32$, $357 \pm 50.55$, and $328.5 \pm 63 \mathrm{nM}$, respectively (Figures 4 (a) and $4(\mathrm{~b}))$. On the other hand, the addition of $5 \mathrm{mM}$ of POM-I or APCP, specific inhibitors of CD39 and CD73, respectively, decreased the capacity of the supernatants to hydrolyze ATP or AMP by more than $90 \%$ in all cases (Figure 4). Interestingly, the addition of doses lower than 5 $\mathrm{mM}(500 \mu \mathrm{M}, 50 \mu \mathrm{M}$, and $5 \mu \mathrm{M})$ of POM-1 or APCP in supernatants of patients positive for HPV-16, which showed the highest contents of CD39 and CD73, suppressed in a dose-dependent manner the conversion from ATP to AMP or AMP to Ado (Figures 5(c) and 5(d)). The inhibition obtained of more than $50 \%$ supports the specific effect of these inhibitors. These results suggest that HPV-16 infection in CIN-1 patients can lead to the generation of an immunosuppressive microenvironment due to its greater association with higher levels of ectonucleotidases CD39 and CD73 and, therefore, its greater capacity to produce Ado.

3.5. Serum Samples from Patients with CIN-1 Positive for HPV-16 Infection Showed Higher Concentration of TGF- $\beta 1$ Compared with Those from CIN-1 Patients Negative for $H P V-16$ and NDs. It has been suggested that TGF- $\beta 1$ plays a key role in promoting human papillomavirus infection, as well as generating an immunosuppressive state in the local microenvironment of the cervix in HPV-infected women. Additionally, it has been reported that TGF- $\beta 1$ levels increase in correlation with the severity of the lesions, and strong expression of this cytokine has been associated with poor survival in patients with $\mathrm{CeCa}$ [24-26]. Considering that we previously reported that TGF- $\beta 1$ enhances CD73 


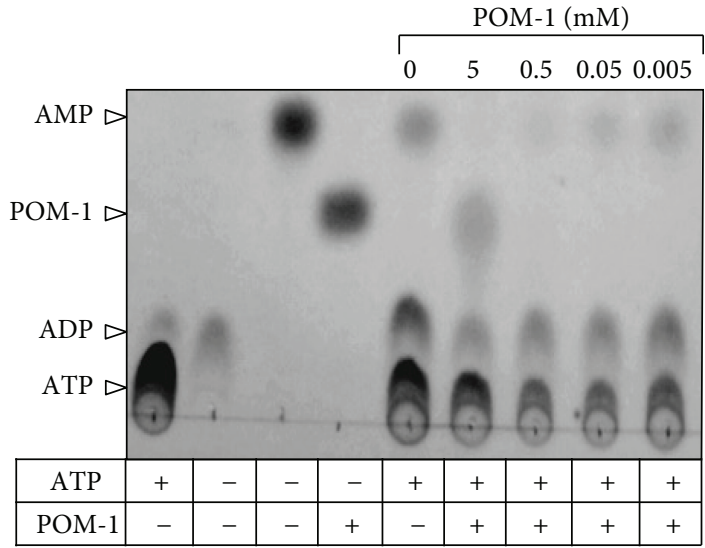

(a)

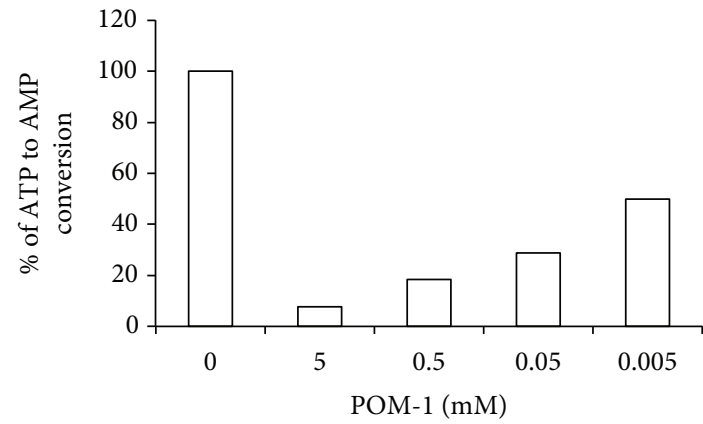

(c)

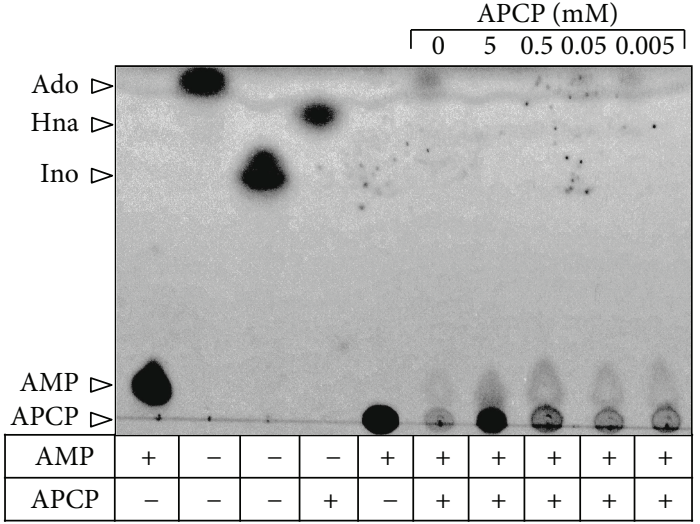

(b)

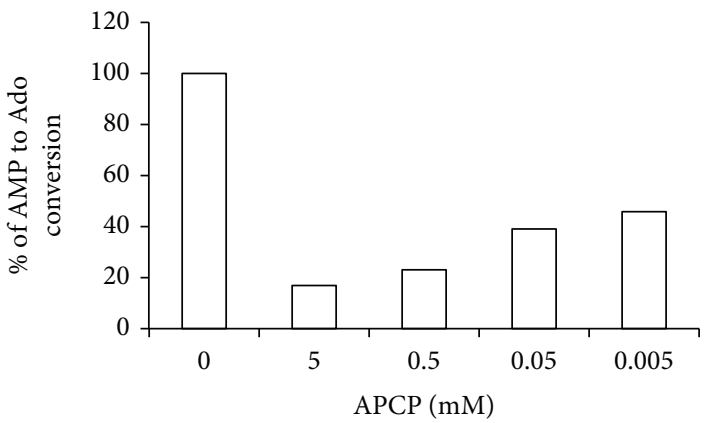

(d)

FIgURE 5: Effect of POM-1 and APCP to inhibit the capacity of supernatants of cervical samples from patients with CIN-1 HPV-16+ to hydrolyze ATP or AMP. Aliquots of $2 \mu \mathrm{g}$ of total protein obtained from the supernatants of cervical samples from patients with CIN-1 HPV-16+ were incubated in the presence of $5 \mathrm{mM}$ of ATP or AMP and in the presence or absence of $(5 \mathrm{mM}, 0.5 \mathrm{mM}, 0.05 \mathrm{mM}$, and $0.005 \mathrm{mM}$ ) of POM-I or APCP, specific inhibitors of CD39 and CD73, respectively. After $72 \mathrm{~h}$ of incubation, the ATP to AMP (a) and AMP to Ado (b) conversions were detected by TLC. The percentages of ATP to AMP (c) and AMP to Ado (d) conversions in the presence of several concentrations of POM-1 or APCP were determined by densitometric analysis in relation to the respective basal conversion (in the absence of the inhibitors), which was considered $100 \%$. A representative assay from three independent experiments is shown.

expression in cervical cancer cells [27], we proceeded to analyze the levels of this cytokine in serum samples of the CIN-1 patients and NDs. Interestingly, patients positive for HPV-16, either by mono-HPV-16 or by coinfection with other HPV genotypes (HPV-16+CI), which showed the highest contents of CD73 in their cervical samples, also showed the highest levels of TGF- $\beta 1$ (Figure 6). The average of TGF- $\beta 1$ concentration contained in serum samples from NDs was $337 \pm 59 \mathrm{pg} / \mathrm{mL}$, while that from CIN-1 patients positive for HPV-16, HPV-16+CI, and HPV-16neg was $768 \pm 85, \quad 735 \pm 65$, and $494 \pm 136 \mathrm{pg} / \mathrm{mL}$, respectively (Figure 6(a)). In addition, we observed a positive correlation between CD73 and TGF- $\beta 1$ contents in both the ND (0.5764, $P<0.001)$ (Figure 6(b)) and CIN-1 (0.695, $P<0.001$ ) groups (Figure $6(\mathrm{c})$ ).

\section{Discussion}

The development of $\mathrm{CeCa}$ is followed by several mechanisms of suppression and evasion of the immune response [28]. For example, during persistent infection with HR-HPV, the levels of viral proteins continue to be low, while capsid proteins are only expressed in the outer layers of the epithelium and, consequently, are out of reach of antigen-presenting cells [29]. Likewise, the pattern of Th1 cytokines, which are produced during the inflammatory state of infection and are important for the activation of CD4+ and CD8+ T lymphocytes and regression of the infection $[30,31]$, is inverted to a pattern of immunosuppressive cytokines, such as interleukin 10 (IL-10) and tumor growth factor beta (TGF- $\beta$ ), whose levels in tissues and plasma are directly correlated with the severity of the infection $[32,33]$, making it more likely to progress to $\mathrm{CeCa}[34,35]$. Additionally, it has been reported that proteins derived from high-risk HPVs, such as HPV-16, interfere with the immune response. For example, E6 and E7 proteins block IFN production by the infected cells [36] and reduce the expression of TLR9 [37] and cytokines, such as IL-8 [38] and IL-18 [39], which are proinflammatory molecules. Likewise, the proteins E5, E6, and E7 downregulate the expression of MHC class I molecules, reducing recognition of the HPV-infected cells by NK cells and by specific CTLs [40].

In turn, several studies have reported that the Ado produced by the functional activity of ectonucleotidases CD39 


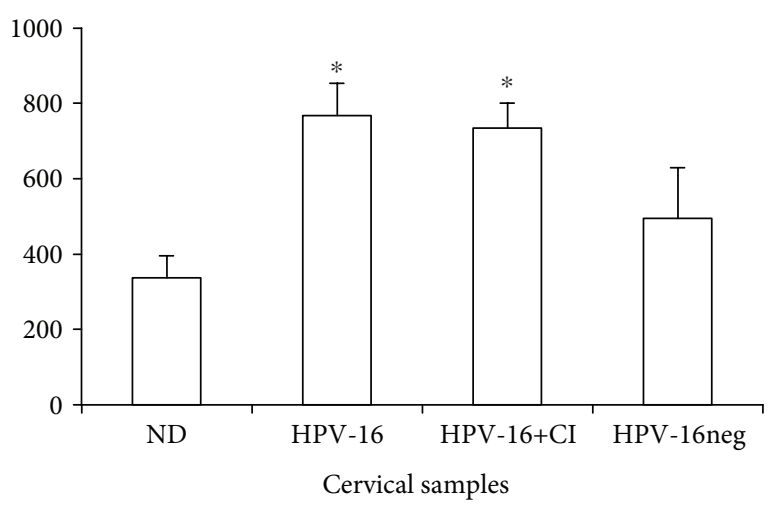

(a)

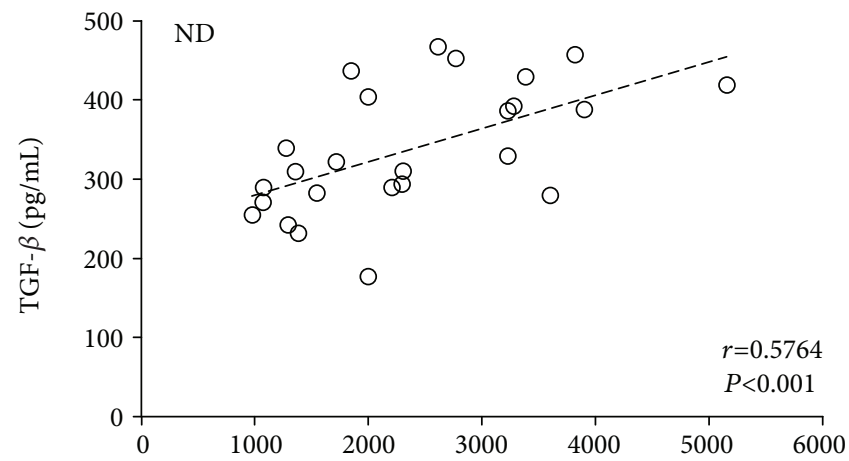

(b)

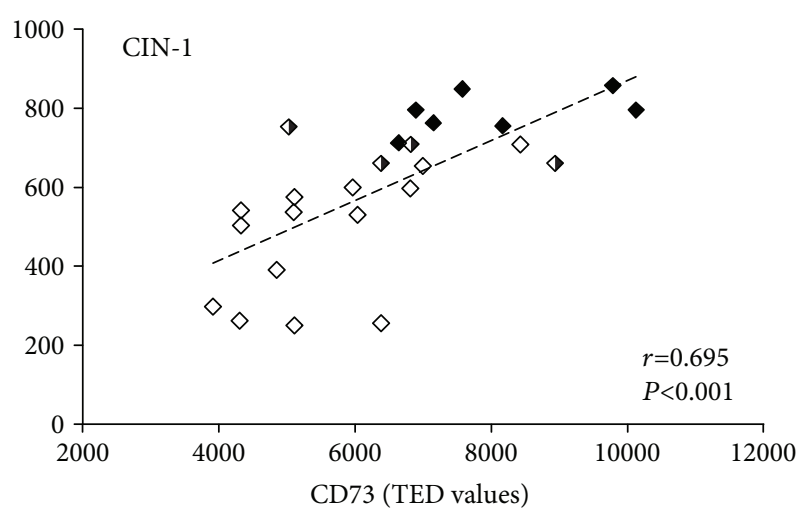

(c)

Figure 6: TGF- $\beta 1$ content in serum samples from NDs and patients with CIN-1 and their correlation with the content of CD73 in their cervical samples. The content of TGF- $\beta 1$ in serum samples derived from NDs and from CIN-1 patients positive for HPV-16, HPV-16+CI, and HPV-16neg is shown (a). Data are representative of three independent experiments, and the averages \pm SEM are shown. $*$ indicates significant difference $(P<0.005)$ in the TGF- $\beta 1$ concentration related to that of NDs. A positive $(r)$ correlation between TGF- $\beta 1$ and TED values of CD73 is shown for ND free of HPV infection $(0.5764, P<0.001)$ (b) and for CIN-1 patients $(0.695, P<0.001)(\mathrm{c})$. The contents of TGF- $\beta 1$ and CD73 are indicated in samples from CIN-1 patients positive for HPV-16 (HPV-16, black diamonds), patients with coinfection with HPV-16 and other HPV types (HPV-16+CI, black and white diamonds), and CIN-1 patients negative for HPV-16 (HPV-16neg, white diamonds). TED: total expression density.

and CD73 participates in the suppression of the antitumor immune response and favors tumor progression in several types of cancer [14, 41-43]. We recently reported that HPV infection promotes the constitutive expression of CD73 in tumor cells of $\mathrm{CeCa}$ to contribute to the production of Ado and to inhibit the effector function of cytotoxic T lymphocytes [15]. However, it is unknown whether HPV infection is associated with the expression of CD39 and CD73 in precancerous lesions of the cervix. Therefore, in this study, we analyzed the hydrolytic activity of these ectonucleotidases in cervical samples from CIN-1 patients positive for HPV and compared them to cervical samples from NDs free of HPV infection. Interestingly, samples from CIN-1 patients, particularly those positive for HPV-16, as either mono- or coinfection with other HPV genotypes, showed higher levels of CD39 and CD73 than those from CIN-1 patients negative for HPV-16 and NDs. Likewise, we detected a greater amount of CD39 and CD73 solubilized in the supernatants 
TABLE 4: Correlation analysis of the clinical data of normal donors and patients with CIN-1 and the expression of CD39 and CD73 in their cervical cytology.

\begin{tabular}{|c|c|c|c|c|c|c|c|}
\hline \multirow[b]{2}{*}{$\begin{array}{l}\text { Cell marker } \\
\text { expression }\end{array}$} & \multicolumn{3}{|c|}{ Normal donors } & \multicolumn{3}{|c|}{ CIN-1 patients } & \multirow[b]{2}{*}{$P$ values } \\
\hline & $\begin{array}{c}\text { Age } \\
\text { (years) }\end{array}$ & $\begin{array}{c}\text { Number of sexual } \\
\text { partners }\end{array}$ & $\begin{array}{l}\text { Number of } \\
\text { pregnancies }\end{array}$ & $\begin{array}{c}\text { Age } \\
\text { (years) }\end{array}$ & $\begin{array}{c}\text { Number of sexual } \\
\text { partners }\end{array}$ & $\begin{array}{l}\text { Number of } \\
\text { pregnancies }\end{array}$ & \\
\hline CD39 & 0.052 & 0.258 & 0.177 & 0.156 & $0.435^{\mathrm{a}}$ & $0.7^{\mathrm{b}}$ & $\begin{array}{l}<0.029^{\mathrm{a}} \\
<0.0001^{\mathrm{b}}\end{array}$ \\
\hline CD73 & 0.26 & $0.439^{c}$ & 0.234 & 0.011 & 0.326 & $0.665^{\mathrm{d}}$ & $\begin{array}{l}<0.027^{\mathrm{c}} \\
<0.0003^{\mathrm{d}}\end{array}$ \\
\hline
\end{tabular}

Values of Pearson's coefficient $(r)$ are shown.

of cervical samples from these patients, which is associated with a high capacity to produce Ado from ATP and AMP hydrolysis. TGF- $\beta$ increases the levels of CD39 and CD73 in activated $\mathrm{T}$ cells and suppressive myeloid cells in both mice [44, 45] and humans [46, 47]. The expression of TGF- $\beta 1$ in CeCa has been directly related to the degree of disease progression $[24,46]$ and to the expression of oncogenes E6 and E7 of HR-HPV [25]. In fact, oncogenes E6 and E7 of HPV-16 induce the activation of the human TGF- $\beta 1$ promoter by recognizing the Sp1 sequence [48]. A recent study revealed that $\mathrm{CeCa}$ tumor cells infected with HR-HPV constitutively produce TGF- $\beta$, which is important for maintaining the expression of CD73 in tumor cells. We showed that the Ado product of the enzymatic activity of CD73 induced the production of TGF- $\beta$ in tumor cells by interacting with $\mathrm{A} 2 \mathrm{AR}$ and $\mathrm{A} 2 \mathrm{BR}$, suggesting an important connection between the adenosinergic pathway and TGF- $\beta$ production in cells infected with HPV [25]. The transcriptional activation of CD39 and CD73 is also regulated by the transcription factor induced by hypoxia-inducible factor 1-alpha (HIF-1 $\alpha)$ [49]. Therefore, TGF- $\beta 1$ stabilizes HIF- $1 \alpha$ [50]. Likewise, it has also been reported that oncogenes E6 and E7 of HPV-16 promote an increase in the expression of HIF-1 $\alpha$ [51]. In the present study, high contents of ectonucleotidases CD39 and CD73 were found in the cervical samples from CIN-1 patients, positive for HPV-16, either by mono-HPV-16 or by coinfection with other HPV genotypes (HPV-16+CI). Interestingly, sera from these patients also showed the highest levels of TGF- $\beta 1$; in consequence, it will be very interesting to know whether these contents of TGF- $\beta$ are capable to inducing and maintaining CD39 and CD73 expression in the cervical microenvironment of CIN-1 patients $\mathrm{HPV}-16+$. On the other hand, these patients exhibited significantly a greater number of sexual partners (averages 3.4 and 2.5) and pregnancies (averages 2.4 and 2.5), respectively, than NDs, whose averages were 1 and 1.2, respectively (Table 3 ). It is important to mention that high correlation between the number of sexual partners and CD39 and the number of pregnancies with the expression of CD39 and CD73 was observed in CIN-1 patients (Table 4 ). In fact, a large number of sexual partners and pregnancies have been reported as the main risk factors associated with persistent HPV infection and an increased risk of developing cervical dysplasia and cancer $[52,53]$. Therefore, the present pilot study suggests that the production of TGF- $\beta$, associated with persistent infection

with HPV-16, may induce and maintain the expression of the ectonucleotidases CD39 and CD73 and contribute to the generation of an immunosuppressive microenvironment in preneoplastic lesions of the uterine cervix and favor its progression. Due to the important role of the adenosinergic pathway in the suppression of the antitumor immune response $[14,41-43]$, its clinical relevance as a therapeutic target to several tumors, and the fact that CD73 expression in cervical cancer cells has been associated with increased metastatic potential [54], it would be interesting to repeat these experiments using a larger number of cervical samples from both patients with CIN-1 presenting infection with both low- and high-risk HPVs and including other lesional tissues, such as CIN-3 and cervical cancer. Consequently, it remains to be determined if CD39 and CD73 could be biomarkers in cervical cancer.

\section{Conclusions}

In this study, we provide evidence that cells obtained from cervical samples of CIN-1 patients positive for HPV-16 showed higher CD39 and CD73 contents compared to cells from samples of CIN-1 patients negative for HPV-16 and NDs. Interestingly, solubilized cervical mucus from these patients also showed higher contents of soluble CD39 and CD73, which were associated with a greater capacity to produce Ado from the hydrolysis of adenosine triphosphate (ATP) and adenosine monophosphate (AMP). In addition, serum samples of these patients showed higher levels of TGF- $\beta$ than those of CIN-1 patients negative for HPV-16 and ND.

These results suggest that persistent infection with HR-HPV, mostly HPV-16, which is present in approximately $50 \%$ of CeCa cases $[55,56]$, may promote the expression of CD39 and CD73 through the production of TGF- $\beta$ in precursor lesions to generate an immunosuppressive microenvironment and allow its progression to $\mathrm{CeCa}$.

\section{Abbreviations}

Ado:

AMP:

APCP:

ARs (A1R, A2AR, A2BR, Adenosine receptors and $A 3 R)$ :

ATP:
Adenosine

Adenosine monophosphate

$5^{\prime}$-( $\alpha, \beta$-Methylene $)$ diphosphate

Adenosine triphosphate 


$\begin{array}{ll}\text { CeCa: } & \text { Cervical cancer } \\ \text { CD39: } & \begin{array}{l}\text { Ectonucleoside triphosphate } \\ \text { diphosphohydrolase-1 }\end{array} \\ \text { CD73: } & 5^{\prime} \text {-Nucleotidase } \\ \text { CI: } & \text { Coinfections } \\ \text { CIN-1: } & \text { Grade } 1 \text { cervical intraepithelial } \\ & \text { neoplasms } \\ \text { HR-HPV: } & \text { High-risk human papillomavirus } \\ \text { NDs: } & \text { Normal donors } \\ \text { PCR: } & \text { Polymerase chain reaction } \\ \text { POM-1: } & \text { Sodium polyoxotungstate } \\ \text { TED: } & \text { Total expression density } \\ \text { TGF- } \beta: & \text { Transforming growth factor- } \beta \\ \text { UPLC: } & \text { Ultraperformance liquid } \\ & \text { chromatography. }\end{array}$

\section{Data Availability}

The data used to support the findings of this study are available from the corresponding author upon request.

\section{Conflicts of Interest}

The authors have no conflicts of interest to declare.

\section{Authors' Contributions}

All authors were involved in drafting the article or revising it critically for important content, and all authors approved the final version to be submitted for publication. AMG had full access to all the data and the accuracy of data analysis. MLMG and AMG were responsible for the study conception and design. SLC, VGS, RGR, RMG, LRAI, DBTP, RCHS, LVC, and SMPT were responsible for the acquisition of data. AMG, MLMG, BWS, and JHM were responsible for the analysis and interpretation of data.

\section{Acknowledgments}

The present study was carried out with the following funds: DGAPA-PAPIIT (Grants IN226516 and IN225519) to MLMG, CONACYT (Grant 240635) to AMG, and the Mexican Social Security Institute (Instituto Mexicano del Seguro Social (IMSS)) (Grant FIS-1161) to AMG. We also appreciate the support provided to Dr. Rosario GarcíaRocha by the Postdoctorate Scholarship Program of the National Autonomous University of Mexico (UNAM by its initials in Spanish). Finally, the authors thank the "Laboratorio Nacional para Servicios Especializados de Investigación, Desarrollo e Innovación (I+ D+ i) para Farmoquímicos y Biotecnológicos (LANSEIDIFarBiotecCONACyT)" for facilitating the use of the UPLC system.

\section{References}

[1] J. Ferlay, I. Soerjomataram, R. Dikshit et al., "Cancer incidence and mortality worldwide: sources, methods and major patterns in GLOBOCAN 2012," International Journal of Cancer, vol. 136, no. 5, pp. E359-E386, 2015.
[2] F. Bray, J. Ferlay, I. Soerjomataram, R. L. Siegel, L. A. Torre, and A. Jemal, "Global cancer statistics 2018: GLOBOCAN estimates of incidence and mortality worldwide for 36 cancers in 185 countries," CA: A Cancer Journal of Clinicians, vol. 68, no. 6, pp. 394-424, 2018.

[3] Y. Ma, R. Madupu, U. Karaoz et al., "Human papillomavirus community in healthy persons, defined by metagenomics analysis of human microbiome project shotgun sequencing data sets," Journal of Virology, vol. 88, no. 9, pp. 4786-4797, 2014.

[4] N. Muñoz, F. X. Bosch, S. de Sanjosé et al., "Epidemiologic classification of human papillomavirus types associated with cervical cancer," New England Journal of Medicine, vol. 348, no. 6, pp. 518-527, 2003.

[5] G. M. Clifford, R. K. Rana, S. Franceschi, J. S. Smith, G. Gough, and J. M. Pimenta, "Human papillomavirus genotype distribution in low-grade cervical lesions: comparison by geographic region and with cervical cancer," Cancer Epidemiology Biomarkers \& Prevention, vol. 14, no. 5, pp. 1157-1164, 2005.

[6] C. B. J. Woodman, S. I. Collins, and L. S. Young, "The natural history of cervical HPV infection: unresolved issues," Nature Reviews Cancer, vol. 7, no. 1, pp. 11-22, 2007.

[7] J. Melnikow, J. Nuovo, A. R. Willan, B. K. Chan, and L. P. Howell, "Natural history of cervical squamous intraepithelial lesions: a meta-analysis," Obstetrics \& Gynecology, vol. 92, no. 4, pp. 727-735, 1998.

[8] A. B. Moscicki, S. Shiboski, N. K. Hills et al., "Regression of low-grade squamous intra-epithelial lesions in young women," The Lancet, vol. 364, no. 9446, pp. 1678-1683, 2004.

[9] A. Kobayashi, V. Weinberg, T. Darragh, and K. SmithMcCune, "Evolving immunosuppressive microenvironment during human cervical carcinogenesis," Mucosal Immunology, vol. 1, no. 5, pp. 412-420, 2008.

[10] A. Bahreyni, S. S. Samani, E. Ghorbani et al., "Adenosine: an endogenous mediator in the pathogenesis of gynecological cancer," Cellular Physiology, vol. 233, no. 4, pp. 2715-2722, 2018.

[11] A. Ohta and M. Sitkovsky, "Role of G-protein-coupled adenosine receptors in downregulation of inflammation and protection from tissue damage," Nature, vol. 414, no. 6866, pp. 916-920, 2001.

[12] A. Ohta, "A metabolic immune checkpoint: adenosine in tumor microenvironment," Frontiers in Immunology, vol. 7, p. 109, 2016.

[13] L. Antonioli, P. Pacher, E. S. Vizi, and G. Haskó, "CD39 and CD73 in immunity and inflammation," Trends in Molecular Medicine, vol. 19, no. 6, pp. 355-367, 2013.

[14] L. Antonioli, G. G. Yegutkin, P. Pacher, C. Blandizzi, and G. Haskó, "Anti-CD73 in cancer immunotherapy: awakening new opportunities," Trends in Cancer, vol. 2, no. 2, pp. 95-109, 2016.

[15] M. L. Mora-García, L. R. Ávila-Ibarra, R. García-Rocha et al., "Cervical cancer cells suppress effector functions of cytotoxic T cells through the adenosinergic pathway," Cellular Immunology, vol. 320, pp. 46-55, 2017.

[16] R. M. Richart, "Natural history of cervical intraepithelial neoplasia," Clinical Obstetrics and Gynecology, vol. 10, no. 4, pp. 748-784, 1967.

[17] C. Philippeos, S. B. Telerman, B. Oulès et al., "Spatial and single-cell transcriptional profiling identifies functionally distinct human dermal fibroblast subpopulations," The Journal of investigative dermatology, vol. 138, no. 4, pp. 811-825, 2018. 
[18] S. Serra, A. L. Horenstein, T. Vaisitti et al., "CD73-generated extracellular adenosine in chronic lymphocytic leukemia creates local conditions counteracting drug-induced cell death," Blood, vol. 118, no. 23, pp. 6141-6152, 2011.

[19] M. de Lourdes Mora-García, R. García-Rocha, O. MoralesRamírez et al., "Mesenchymal stromal cells derived from cervical cancer produce high amounts of adenosine to suppress cytotoxic T lymphocyte functions," Journal of Translational Medicine, vol. 14, no. 1, p. 302, 2016.

[20] J. K. Grünewald and A. J. Ridley, "CD73 represses proinflammatory responses in human endothelial cells," Journal of Inflammation, vol. 7, no. 1, p. 10, 2010.

[21] A. Honegger, J. Leitz, J. Bulkescher, K. Hoppe-Seyler, and F. Hoppe-Seyler, "Silencing of human papillomavirus (HPV)E6/E7oncogene expression affects both the contents and the amounts of extracellular microvesicles released from HPV-positive cancer cells," International Journal of Cancer, vol. 133, no. 7, pp. 1631-1642, 2013.

[22] M. Simons and G. Raposo, "Exosomes-vesicular carriers for intercellular communication," Current Opinion in Cell Biology, vol. 21, no. 4, pp. 575-581, 2009.

[23] C. Thery, M. Ostrowski, and E. Segura, "Membrane vesicles as conveyors of immune responses," Nature Reviews Immunology, vol. 9, no. 8, pp. 581-593, 2009.

[24] H. Zhu, H. Luo, Z. Shen, X. Hu, L. Sun, and X. Zhu, “Transforming growth factor- $\beta 1$ in carcinogenesis, progression, and therapy in cervical cancer," Tumour Biology, vol. 37, no. 6, pp. 7075-7083, 2016.

[25] I. V. Iancu, A. Botezatu, C. D. Goia-Rusanu et al., “TGF-beta signalling pathway factors in HPV-induced cervical lesions," Roumanian Archives of Microbiology and Immunology, vol. 69, no. 3, pp. 113-118, 2010.

[26] K. Torres-Poveda, M. Bahena-Román, C. Madrid-González et al., "Role of IL-10 and TGF- $\beta 1$ in local immunosuppression in HPV-associated cervical neoplasia," World Journal of Clinical Oncology, vol. 5, no. 4, pp. 753-763, 2014.

[27] R. García-Rocha, A. Monroy-García, J. Hernández-Montes et al., "Cervical cancer cells produce TGF- $\beta 1$ through the CD73-adenosine pathway and maintain CD73 expression through the autocrine activity of TGF- $\beta 1$," Cytokine, 2018.

[28] S. Kanodia, L. Fahey, and W. M. Kast, "Mechanisms used by human papillomaviruses to escape the host immune response," Current Cancer Drug Targets, vol. 7, no. 1, pp. 7989, 2007

[29] J. Doorbar, W. Quint, L. Banks et al., "The biology and lifecycle of human papillomaviruses," Vaccine, vol. 30, no. 5, pp. F55-F70, 2012.

[30] Y. Xu, K. J. Zhu, N. Zhu, D. H. Jiang, X. Z. Chen, and H. Cheng, "Expression of Foxp $3^{+} \mathrm{CD} 4^{+} \mathrm{CD} 25^{+}$regulatory $\mathrm{T}$ cells and $\mathrm{Th} 1 / \mathrm{Th} 2, \mathrm{Tc} 1 / \mathrm{Tc} 2$ profiles in the peripheral blood of patients with condyloma acuminatum," Clinical and Experimental Dermatology, vol. 34, no. 2, pp. 229-235, 2009.

[31] M. Scott, D. P. Stites, and A. B. Moscicki, "Th1 cytokine patterns in cervical human papillomavirus infection," Clinical and Diagnostic Laboratory Immunology, vol. 6, no. 5, pp. 751-755, 1999.

[32] N. Jacobs, S. L. Giannini, J. Doyen et al., "Inverse modulation of IL-10 and IL-12 in the blood of women with preneoplastic lesions of the uterine cervix," Clinical and Experimental Immunology, vol. 111, no. 1, pp. 219-224, 1998.
[33] M. Clerici, E. Ferrario, D. Trabattoni et al., "Cytokine production patterns in cervical intraepithelial neoplasia: association with human papillomavirus infection," JNCI Journal of the National Cancer Institute, vol. 89, no. 3, pp. 245-250, 1997.

[34] J. M. Alcocer-González, J. Berumen, R. Taméz-Guerra et al., "In vivo expression of immunosuppressive cytokines in human papillomavirus-transformed cervical cancer cells," Viral Immunology, vol. 19, no. 3, pp. 481-491, 2006.

[35] Q. Feng, H. Wei, J. Morihara et al., "Th2 type inflammation promotes the gradual progression of HPV-infected cervical cells to cervical carcinoma," Gynecologic Oncology, vol. 127, no. 2, pp. 412-419, 2012.

[36] M. Nees, J. M. Geoghegan, T. Hyman, S. Frank, L. Miller, and C. D. Woodworth, "Papillomavirus type 16 oncogenes downregulate expression of interferon-responsive genes and upregulate proliferation-associated and NF- $\kappa \mathrm{B}$-responsive genes in cervical keratinocytes," Journal of Virology, vol. 75, no. 9, pp. 4283-4296, 2001.

[37] U. A. Hasan, E. Bates, F. Takeshita et al., "TLR9 expression and function is abolished by the cervical cancer-associated human papillomavirus type 16," The Journal of Immunology, vol. 178, no. 5, pp. 3186-3197, 2007.

[38] S. M. Huang and D. J. McCance, "Down regulation of the interleukin-8 promoter by human papillomavirus type 16 E6 and E7 through effects on CREB binding protein/p300 and P/CAF," Journal of virology, vol. 76, no. 17, pp. 8710-8721, 2002.

[39] S. J. Lee, Y. S. Cho, M. C. Cho et al., "Both E6 and E7 oncoproteins of human papillomavirus 16 inhibit IL-18-induced IFN- $\gamma$ production in human peripheral blood mononuclear and NK cells," The Journal of Immunology, vol. 167, no. 1, pp. 497504, 2001.

[40] C. Heller, T. Weisser, A. Mueller-Schickert et al., "Identification of key amino acid residues that determine the ability of high risk HPV16-E7 to dysregulate major histocompatibility complex class I expression," Journal of Biological Chemistry, vol. 286, no. 13, pp. 10983-10997, 2011.

[41] P. A. Beavis, J. Stagg, P. K. Darcy, and M. J. Smyth, "CD73: a potent suppressor of antitumor immune responses," Trends in Immunology, vol. 33, no. 5, pp. 231-237, 2012.

[42] J. Bastid, A. Cottalorda-Regairaz, G. Alberici, N. Bonnefoy, J. F. Eliaou, and A. Bensussan, "ENTPD1/CD39 is a promising therapeutic target in oncology," Oncogene, vol. 32, no. 14, pp. 1743-1751, 2013.

[43] S. C. Robson, J. Sévigny, and H. Zimmermann, “The E NTPDase family of ectonucleotidases: structure function relationships and pathophysiological significance," Purinergic Signalling, vol. 2, no. 2, pp. 409-430, 2006.

[44] S. V. Ryzhov, M. W. Pickup, A. Chytil et al., "Role of TGF- $\beta$ signaling in generation of $\mathrm{CD} 39^{+} \mathrm{CD} 73^{+}$myeloid cells in tumors," The Journal of Immunology, vol. 193, no. 6, pp. 3155-3164, 2014.

[45] J. Li, L. Wang, X. Chen et al., "CD39/CD73 upregulation on myeloid-derived suppressor cells via TGF- $\beta$-mTOR-HIF-1 signaling in patients with nonsmall cell lung cancer," Oncoimmunology, vol. 6, no. 6, 2017.

[46] J. T. Comerci Jr, C. D. Runowicz, K. C. Flanders et al., “Altered expression of transforming growth factor- $\beta 1$ in cervical neoplasia as an early biomarker in carcinogenesis of the uterine cervix," Cancer, vol. 77, no. 6, pp. 1107-1114, 1996. 
[47] C. W. Daniel and S. D. Robinson, "Regulation of mammary growth and function by TGF- $\beta$," Molecular Reproduction and Development, vol. 32, no. 2, pp. 145-151, 1992.

[48] O. Peralta-Zaragoza, V. Bermúdez-Morales, L. GutiérrezXicotencatl, J. Alcocer-González, F. Recillas-Targa, and V. Madrid-Marina, "E6 and E7 oncoproteins from human papillomavirus type 16 induce activation of human transforming growth factor $\beta_{1}$ promoter throughout Sp1 recognition sequence," Viral Immunology, vol. 19, no. 3, pp. 468-480, 2006.

[49] S. McMahon, M. Charbonneau, S. Grandmont, D. E. Richard, and C. M. Dubois, "Transforming growth factor $\beta 1$ induces hypoxia-inducible factor-1 stabilization through selective inhibition of PHD2 expression," Journal of Biological Chemistry, vol. 281, no. 34, pp. 24171-24181, 2006.

[50] K. Synnestvedt, G. T. Furuta, K. M. Comerford et al., "Ecto-5' -nucleotidase (CD73) regulation by hypoxia-inducible factor1 mediates permeability changes in intestinal epithelia," Journal of Clinical Investigation, vol. 110, no. 7, pp. 993-1002, 2002.

[51] X. Tang, Q. Zhang, J. Nishitani, J. Brown, S. Shi, and A. D. le, "Overexpression of human papillomavirus type 16 oncoproteins enhances hypoxia-inducible factor $1 \alpha$ protein accumulation and vascular endothelial growth factor expression in human cervical carcinoma cells," Clinical Cancer Research, vol. 13, no. 9, pp. 2568-2576, 2007.

[52] A. R. Giuliano, M. Papenfuss, A. Schneider, M. Nour, and K. Hatch, "Risk factors for high-risk type human papillomavirus infection among Mexican-American women," Cancer Epidemiology Biomarkers and Prevention, vol. 8, no. 7, pp. 615-620, 1999.

[53] E. M. Smith, S. R. Johnson, D. Jiang et al., "The association between pregnancy and human papilloma virus prevalence," Cancer Detection and Prevention, vol. 15, no. 5, pp. 397-402, 1991.

[54] Z. W. Gao, H. P. Wang, F. Lin et al., “CD73 promotes proliferation and migration of human cervical cancer cells independent of its enzyme activity," BMC Cancer, vol. 17, no. 1, p. 135, 2017.

[55] D. Forman, C. de Martel, C. J. Lacey et al., "Global burden of human papillomavirus and related diseases," Vaccine, vol. 30, no. 5, pp. F12-F23, 2012.

[56] J. M. M. Walboomers, M. V. Jacobs, M. M. Manos et al., "Human papillomavirus is a necessary cause of invasive cervical cancer worldwide," The Journal of Pathology, vol. 189, no. 1, pp. 12-19, 1999. 


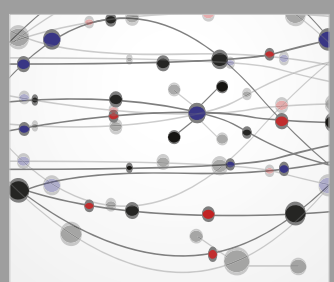

The Scientific World Journal
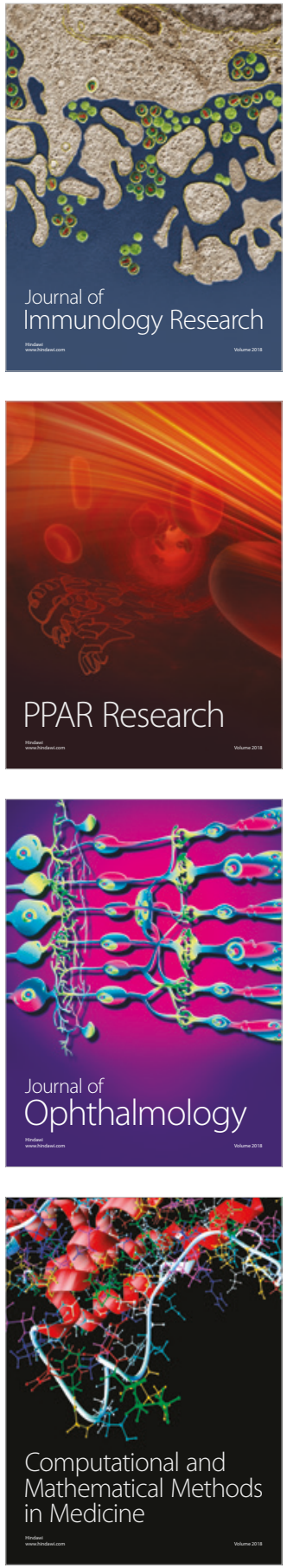

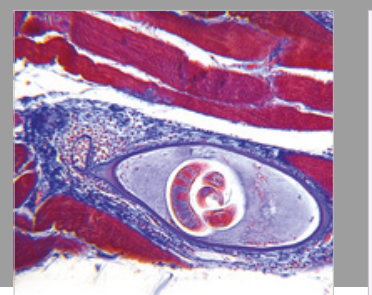

Gastroenterology Research and Practice

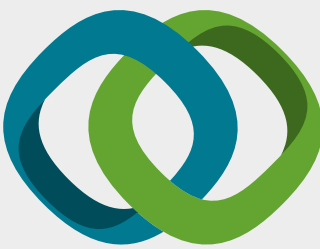

\section{Hindawi}

Submit your manuscripts at

www.hindawi.com
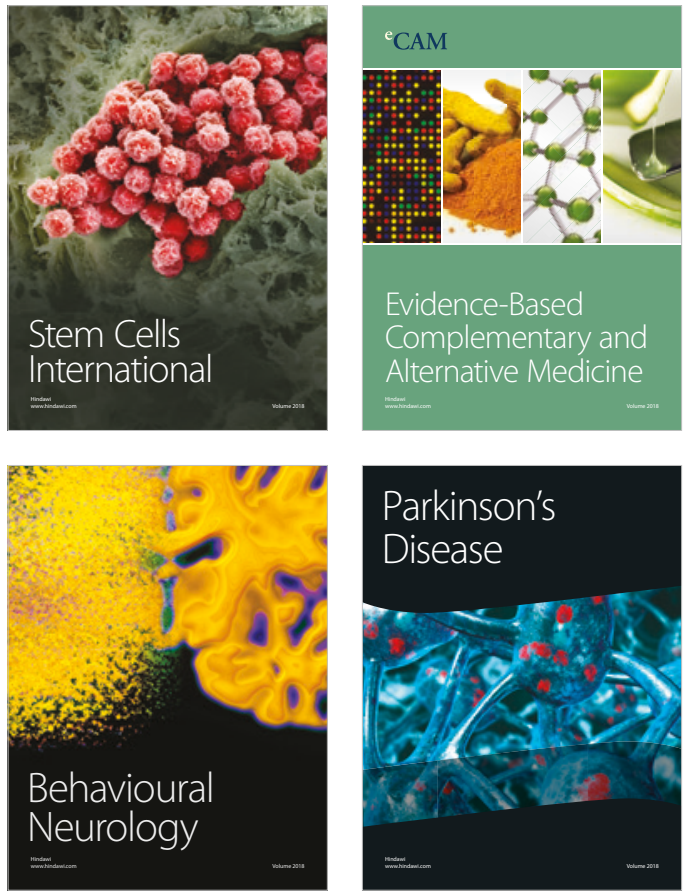

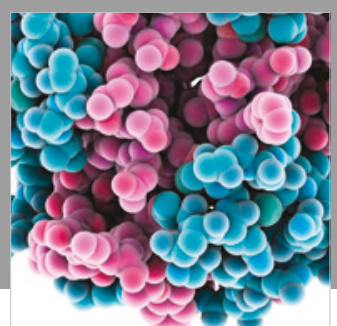

ournal of

Diabetes Research

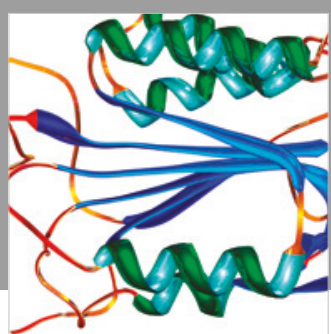

Disease Markers
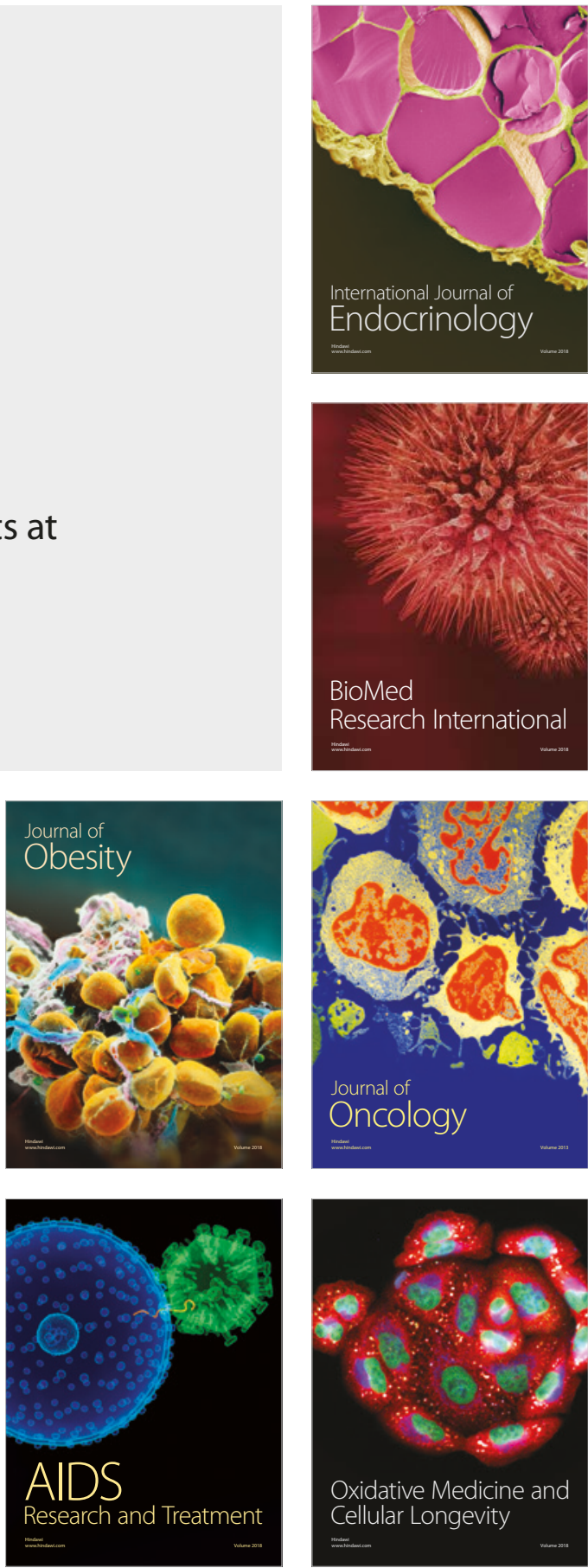